\title{
OS MATIZES DA REALIDADE EM O AMANUENSE BELMIRO
}

\author{
Alex Alves Fogal \\ Doutorando em Literatura Brasileira do Programa de Pós-Graduação em Estudos \\ Literários / UFMG
}

\begin{abstract}
RESUMO
O presente artigo buscará demonstrar que, apesar da forte presença dos aspectos intimistas e psicológicos no romance $O$ amanuense Belmiro, de Cyro dos Anjos, o elemento real se mostra matizado na constituição narrativa, através de um processo de mediação entre a forma e o mundo social.
\end{abstract}

\section{PALAVRAS-CHAVE}

Forma, intimismo, realidade, $O$ amanuense Belmiro

\section{INTRODUÇÃO}

O romance $O$ amanuense Belmiro, do escritor Cyro dos Anjos, é tradicionalmente reconhecido por seu aspecto lírico e sua forma intimista. Devido ao fato de ser narrado em primeira pessoa por um narrador-personagem melancólico e sentimentalista, o caráter psicológico e subjetivista da narrativa acabou por se destacar. Porém, conforme algumas abordagens mais atentas já mostraram, o livro não se limita ao âmbito das impressões e devaneios, mas sim apresenta um apurado movimento bascular entre a realidade e a imaginação, conforme aponta Antonio Candido em seu estudo intitulado "Estratégia”. 1

A partir dessa perspectiva, O amanuense Belmiro deixa de ser visto apenas como um romance distanciado de seu tempo, fechado hermeticamente na intimidade do narrador Belmiro e compreendido como solução alternativa ao forte discurso social dos romances de $30 .^{2}$ É justamente dessa problemática que se origina a questão central a ser

\footnotetext{
${ }^{1}$ CANDIDO. Estratégia, p. 78.

${ }^{2}$ NOBILE. A recepção crítica de O amanuense Belmiro, de Cyro dos Anjos (1937), p. 32.
} 
discutida no presente trabalho. Vejamos: se o romance articula estrategicamente os arroubos líricos de Belmiro a uma concepção lúcida e representativa do plano real, o que lhe garante tal movimento? A ideia central desta pequena análise é mostrar que o que garante tal articulação é uma concepção de realismo bastante matizada, que foge aos ditames do Realismo enquanto escola. ${ }^{3}$ A partir da análise de alguns trechos do romance, o objetivo é demonstrar que o modelo de representação empregado por Cyro dos Anjos na obra se baseia numa concepção figural e complexa da realidade na qual a expressão de sentimentos e sensações está repleta de historicidade, e, inversamente a isso, a relação com a realidade referencial se dá de modo bastante lírico.

\section{A REALIDADE TRANSFIGURADA DO AMANUENSE}

No livro O amanuense Belmiro, é visível que, apesar do apego ao que não é substancial e concreto, o enredo do romance fundamenta-se basicamente na mescla entre as fugitivas imagens do passado e as forças vitais que impelem o homem para a realidade, sendo estabelecido assim um movimento dúbio e contraditório, capaz de mostrar o presente à consciência do homem sob aspectos míticos e formas pretéritas. Nem mesmo essa vontade de se fechar no passado e nas recordações retira a importância que a realidade presente possui na obra. Em outras palavras, a estratégia de construção do romance apresenta um modo de composição baseado numa dialética entre o lírico e o social, sem que nenhum dos dois polos possa ser entendido de modo independente, já que na conformação estética do livro os traços psicológicos e subjetivos não estão em contraposição às descrições e interpretações da realidade. Esse movimento ambíguo funciona como o principal dispositivo da narrativa, desenvolvendo o movimento de báscula.

Essa alternância entre uma construção narrativa baseada na realidade circundante e outra de caráter intimista está presente no romance do início ao fim, porém o modo como é apresentada sofre algumas variações. Em certos trechos, essa relação acontece de modo mais espaçado, organizada em parágrafos diferentes, o que a torna mais visível. Nos trechos a seguir, tal tendência aparece de modo a situar o ponto de vista pelo qual o narrador observa o mundo:

\footnotetext{
${ }^{3}$ AUERBACH. Mimesis: a representação da realidade na literatura ocidental, p. 161-167.
} 
A multidão me revela, assim, que há coisas extraordinárias, vibrações estranhas, há um mundo diverso do meu e com o qual tentarei, em vão, comunicar-me. No seu bojo, tocamos seres cuja existência nos surpreende quase dolorosamente, tão certo estávamos de que nada havia no espaço além do nosso sistema. ${ }^{4}$

Aqui, o narrador entra em contato com uma multidão de foliões situados em uma praça de Belo Horizonte durante a festa de carnaval na cidade e decide prestar atenção nas pessoas que se divertem. Se observarmos atentamente o fragmento, veremos que as reflexões se direcionam para uma realidade mais exterior, ou como o próprio Belmiro diz, para a análise de um ambiente que extrapola sua constituição psicológica: é a “multidão” que lhe revela “coisas extraordinárias”, e a consciência de que o mundo não é constituído apenas pelo seu próprio “sistema” é reforçada. Mesmo mais ao final da passagem, quando a narrativa assume um tom mais íntimo (fala-se de "existência” e das sensações proporcionadas pelo contato com os carnavalescos), o que se vê é que sua atenção se dirige para indivíduos estranhos, observando neles algo que foge à sua pura individualidade. Já o trecho a seguir, situado no parágrafo que vem logo depois do citado acima, apresenta uma perspectiva distinta, pois é explícita a construção a partir de aspectos mais íntimos:

Habituei-me a uma paisagem confinada e a um horizonte quase doméstico. No seu âmbito poucas são as imagens do presente e muitas as do passado. E se tal vida é melancólica, trata-se de uma sorte de melancolia a que meu espírito se adaptou e que, portanto, não desperta novas reações.

Como foi dito anteriormente, o método é desempenhado aqui de maneira intervalada, já que seu movimento oscilante ocorre na passagem de um parágrafo ao outro. Nesse segundo trecho selecionado, pode-se ver que, inversamente ao primeiro, a narração está fundamentada por um olhar subjetivo, construído basicamente por impressões do narrador. Os próprios termos utilizados pelo burocrata, como “confinada”, “doméstico” e “melancólica”, dão ênfase à construção de um universo interior. Além disso, ao contrário do que acontece nos momentos do romance, em que o ponto de vista referencial predomina, aqui, como nos diz o próprio amanuense, é o passado que se destaca, visto que está afundado em um surto de nostalgia. Outro

\footnotetext{
${ }^{4}$ ANJOS. O amanuense Belmiro, p. 36.

${ }^{5}$ ANJOS. O amanuense Belmiro, p. 36.
} 
momento no qual se dá essa alternância pode ser observado nos dois fragmentos que se encontram a seguir:

Os apitos das duas fábricas próximas (a da frente, que é de toalhas, e a que se acha por trás do lote vago, que é a de calçados) sempre me despertam a tais horas. E a força do hábito faz com que, aos domingos ou dias santos, embora não haja trabalho, eu acorde assustado, ouvindo qualquer apito do outro mundo. ${ }^{6}$

Nesse exemplo, é possível perceber que Belmiro inicia a narração a partir de um estilo mais objetivo, apegado às circunstâncias e aos fatos. A partir do que é descrito na narrativa, podemos remeter diretamente ao processo de industrialização pelo qual a cidade de Belo Horizonte passava no período. O narrador dedica-se a localizar especificamente a posição das duas fábricas em relação ao local de sua moradia, e até mesmo os produtos fabricados nas indústrias são apontados, como se o objetivo fosse criar uma reconstrução do cenário descrito na mente do leitor.

No parágrafo seguinte, a narração já assume um aspecto diverso, abandonando o caráter descritivo e constituindo-se a partir de uma perspectiva mais onírica:

Devo também esclarecer que sempre engano os donos das fábricas reais e o da fábrica imaginária dos domingos: acabados os apitos, ponho-me de novo a dormir, embalado pela música das máquinas. ${ }^{7}$

Não é difícil notar que nesse exemplo o amanuense subjetiviza a narrativa tudo começa a ter sentido apenas em relação ao seu mundo interior. Enquanto no trecho anterior a descrição era minuciosa, buscando-se uma representação calcada em aspectos reais, aqui já se fala em “apito de outro mundo” e de “fábricas imaginárias”, expressando uma mudança de rumo em direção a uma narração mais fantasiosa. Ocorre uma mudança no tom distanciado e informativo que se notava na narração para uma construção de cunho lírico e individual: o som das máquinas é capaz apenas de embalar o sono do personagem, e as indústrias - com seus trabalhadores e apitos - deixam de ser uma referência concreta do mundo empírico, passando a servir apenas como um meio para que o narrador retorne ao sono e ao sonho. Aqui os ruídos causados pelo trabalho de produção das fábricas não aparecem relacionados diretamente ao crescimento da cidade e sua transformação, mas dizem respeito apenas ao sono matinal do habitante da rua Erê aos domingos.

\footnotetext{
${ }^{6}$ ANJOS. O amanuense Belmiro, p. 104.

${ }^{7}$ ANJOS. O amanuense Belmiro, p. 104.
} 
Nos exemplos apontados acima, o tipo de movimento observável parte de um estilo narrativo de cunho exterior para outro, de caráter íntimo e subjetivo, visto que a própria perspectiva do narrador revela-nos, no primeiro trecho, que seu olhar está direcionado para o exterior, enquanto no segundo, o ponto de vista é dirigido para a constituição interior do narrador-personagem, tendo como base suas divagações.

Contudo, outras passagens revelam também uma movimentação em sentido inverso ao descrito anteriormente, partindo de um plano subjetivo para outro, mais ligado à realidade. Um exemplo para isso pode ser encontrado quando o personagemnarrador se dedicava a pensar seu desejo de escrever um livro e as peculiaridades que envolvem o ato da criação literária:

Se cá dentro deste peito celibatário tem havido coisas épicas, um Belmiro (que costuma assobiar operetas) insinua que as epopéias de um amanuense encontram seu lugar justo é dentro da cesta. Este mesmo Belmiro sofisticado foi quem matou dois outros livros no decurso dos dez últimos anos. Um, no terceiro capítulo, e outro na décima linha da segunda página. ${ }^{8}$

Desde o início do fragmento já podemos constatar seu forte subjetivismo, pois a reflexão parte de “dentro do peito” do narrador. Não somente a posição que adotada para narrar, mas a própria constituição da linguagem indica uma carga lírica e poética marcante, como se vê a partir do emprego conotativo do termo "epopeias" e do verbo “matar”. Logo em seguida, poucas linhas à frente no desenvolvimento do romance, esse raciocínio é cortado bruscamente por uma consideração acerca de seu cotidiano:

On revient toujors: hoje recomeça a mesma aventura, no mesmo quarto envelhecido desta patética rua Erê, enquanto as carrocinhas de pão começam a percorrer o Prado e meus amigos operários devem estar procurando o caminho da fábrica de calçados. ${ }^{9}$

Nessa passagem, é possível observar um forte movimento de alternância entre o plano interior e o exterior. Após tecer considerações sobre o caráter épico que suas rememorações poderiam assumir se aproveitadas num livro e divagar sobre a metafísica que existe em abandonar a escrita de uma obra literária, Belmiro fixa sua atenção em coisas mais palpáveis: pensa na humilde condição de sua morada, nos vendedores de pão que atravessam seu bairro logo de manhã cedo e no proletariado da cidade. O

\footnotetext{
${ }^{8}$ ANJOS. O amanuense Belmiro, p. 32.

${ }^{9}$ ANJOS. O amanuense Belmiro, p. 32.
} 
amanuense vai de um plano lírico em direção a uma representação mais crua e direta da realidade imediata, sem que haja fortes deformações dos objetos narrados.

Outro momento no qual se nota algo parecido pode ser visto no capítulo em que Belmiro é levado por Glicério a um baile da alta sociedade de Belo Horizonte. O amigo do amanuense diz se tratar apenas de uma simples partida de pôquer, pois sabe que, do contrário, o burocrata se sentiria encabulado em comparecer em tal ambiente. Contudo, o constrangimento do personagem-narrador é imediato quando percebe que a banal noite de jogatina na verdade era uma festa. Segundo suas próprias palavras:

Dissolveu-se a roda, afastaram-se os móveis e, abandonado pelo Glicério, assentei-me em uma poltrona, a um canto. As moças não me notavam, mas eu bem as via, para festa dos olhos e malinconia do espírito. Traziam-me uma imagem da vida que foge, e foge sem dó. Nada mais depressivo que sentir outras gerações surgirem depois da nossa e nos disputarem espaço. A vida nos logra, cada dia, mas nós a amamos, como o amante que ainda mais ama a companheira, quando sabe que ela o engana. Ai de nós, os que vamos passando. ${ }^{10}$.

Nesse trecho, é nítida a feição lírica da reflexão do narrador sobre a efemeridade da vida e do tempo, pois, a partir de um transbordamento de seu interior, Belmiro começa a se evadir do baile no qual se encontra e se perde em devaneios. Como é possível perceber, apenas as primeiras linhas da citação apresentam caráter mais direto e referencial, nas quais o burocrata descreve a movimentação que ocorria a seu redor. Após o início da festa e do seu embaraço, o amanuense passa a ser apenas "olhos” e “espírito”, na verdade, mais espírito (metafísico) do que olhos (físico). Apesar do desejo que a beleza das moças lhe proporciona, o personagem-narrador tem seu espírito cada vez mais tomado pela melancolia, pondo-se a pensar nos tempos idos e na "imagem da vida que foge”. Porém, alguns trechos adiante, o tom da narração já assume outra característica:

Mas não poderei suportar por muito tempo, a tirania de Glicério. Meu lugar é outro e meu clima é bem diverso do desses salões a que ele me transporta. Meu lugar é nesta rua Erê, entre Emília, Francisquinha, Tomé, Prudêncio Gouveia e o velho Giovanni. ${ }^{11}$

Observa-se que o foco já não são os sentimentos e o estado psicológico do amanuense, mas sim as relações sociais. Ele demonstra enfado em relação à atitude de Glicério, que, apesar de saber que Belmiro é um funcionário público de humildes

\footnotetext{
${ }^{10}$ ANJOS. O amanuense Belmiro, p. 63.

${ }^{11}$ ANJOS. O amanuense Belmiro, p. 64.
} 
condições e sem representatividade nos altos círculos da sociedade belo-horizontina, insiste em colocá-lo em situações como essas. Na verdade, o interesse de Glicério em se aproveitar da dose de erudição e dos conhecimentos literários do encolhido amanuense durante essas reuniões filistinas, o que, segundo o jovem arrivista pensa, garantiria-lhe algum prestígio. Assim, vemos que, após um momento de aguda melancolia e desconcerto sentimental, o narrador toma consciência de seu lugar na hierarquia de classes da capital e critica sua função de clown.

As passagens apresentadas e analisadas até aqui permitem que se visualize de maneira muito clara a importância do método ambíguo na estrutura da narrativa, pois o romance segue essa lógica de construção durante todo o seu desenvolvimento. Pensando nesses termos, é importante destacar o raciocínio de Theodor Adorno, para quem o lirismo vai além das emoções e experiências pessoais, sendo possível extrair o universal da mais irrestrita individuação, desde que a apreensão do conteúdo social não seja capaz de "levar para fora da obra de arte, mas sim levar para mais fundo dela”. ${ }^{2}$ Adorno nos mostra que, de modo anacrônico, muitos ainda veem a lírica desvencilhada do peso da objetividade, contudo:

Essa exigência feita à lírica, a exigência da palavra virginal, é em si mesma social. Implica o protesto contra uma situação social que todo indivíduo experimenta como hostil, alienada, fria, opressiva, uma situação que se imprime em negativo na configuração da lírica. ${ }^{13}$

Ao pensarmos na forma adotada por Cyro dos Anjos é importante que entendamos a realização estética de aspecto lírico como algo que não é apenas subjetivo. Esse tipo de interpretação permite enxergar o forte aspecto poético e intimista do livro sem cair no hermetismo, o que evita a tendência de se compreender a lírica a partir da ideia de ilusão sem consequência, como se não pudesse ser concebida como forma de mimese. ${ }^{14}$ Ainda lembrando da ideia de Adorno, é necessário compreender que “a composição lírica tem esperança de extrair, da mais irrestrita individuação, o universal”. 15

Outro modo interessante de entender a questão pode ser encontrada nas reflexões de Georg Lukács sobre o lirismo. O pensador húngaro também aponta o anacronismo

\footnotetext{
${ }^{12}$ ADORNO. Palestra sobre lírica e sociedade, p. 66.

${ }^{13}$ ADORNO. Palestra sobre lírica e sociedade, p. 69.

${ }^{14}$ MERQUIOR. A astúcia da mimese: (ensaios sobre lírica), p. 18-19.

${ }^{15}$ ADORNO. Palestra sobre lírica e sociedade, p. 66.
} 
que predominou por longo tempo ao se pensar a forma lírica, pois esta geralmente foi interpretada apenas como "autorepresentação da interioridade subjetiva, cujas raízes remontariam aos comportamentos mágicos da sociedade primitiva”. ${ }^{16} \mathrm{Na}$ concepção lukácsiana, assim como a forma épica e a dramática, a lírica expressa o real de maneira social, embora nela o processo de representação apresente uma função qualitativamente diversa, posto que o elemento subjetivo se encontra configurado de modo mais específico na dinâmica da obra. Na composição do romance do escritor mineiro, esse tipo de articulação dos dois planos atua de modo efetivo, conforme mostraram os exemplos anteriores.

Nesses trechos já apontados, a traspassação de uma construção intimista para outra realista (e vice-versa) ocorre de modo mais espaçado: ou há uma mudança nítida no estilo de linguagem (como no exemplo das fábricas) ou ocorre uma alteração em relação à focalização do objeto narrativo (o exemplo do baile). Nas passagens que veremos a seguir, esse movimento de estilização é empreendido de um jeito mais apurado, pois ocorre de maneira espaçada integrada. Assim, é apresentada uma conexão mais sólida entre lirismo e realidade, visto que a expressão subjetiva quase se mistura com as referências ao plano real e aos elementos cotidianos. Um exemplo no qual as duas formas narrativas se encontram fortemente unidas pode ser encontrado na seguinte citação:

Do alpendre da casa, na velha cadeira austríaca, fiquei a olhar os transeuntes. A rua Erê não é atrativa, neste particular, com sua reduzida fauna humana. Talvez seja isso o que sempre me leva a passear o pensamento por outras ruas e por outros tempos. ${ }^{17}$

Aqui, o aspecto referencial é muito forte no início da passagem, pois como se vê, a narração começa a partir da delimitação do local de onde se fala. Porém, o que é mais interessante notar é a propensão do amanuense em relacionar o lirismo e a fantasia ao cenário, demonstrando como seu intimismo não brota apenas de sua própria sentimentalidade ou estado anímico, mas também do espaço exterior, instaurando um movimento de mão dupla. Belmiro aponta o espaço da cidade que habita como motivo de seus devaneios, uma vez que menciona a falta de atratividade e movimentação da região na qual fica sua residência, situada na parte periférica da cidade. Portanto,segundo a lógica do burocrata, a hipertrofia de sua subjetividade está

\footnotetext{
${ }^{16}$ LUKACS. A característica mais geral do reflexo lírico, p. 245.

${ }^{17}$ ANJOS. O amanuense Belmiro, p. 26.
} 
fortemente associada com o aquilo que lhe é externo, uma vez que se observa a interpenetração efetiva entre a paisagem e a psicologia do personagem.

Outro exemplo para visualizar esse tipo de formulação encontra-se na parte em que o narrador reflete sobre a decomposição do sistema dos Borbas, ou seja, da decadência de sua linhagem familiar:

Na fazenda, na Vila, no curso. Meu consolo é que sou um grande amanuense. Um burocrata! exclamava o velho com desprezo. Coitado do velho. Queria fazer-me agrônomo. Ou então, agrimensor formado, e andava por lá, a febre das divisões de terras. Era contra os princípios do velho o bacharelato em qualquer ramo de ciências ou letras. "Temos doutores demais, dizia ele. Precisamos é de braços para a lavoura." Mas dei em droga na fazenda e andei zanzando pela Vila, metido em serenatas e noutras relaxações. Coitado do velho. Neguei as virtudes da estirpe. Sou um fruto chocho do ramo vigoroso dos Borbas, que teve seu brilho rural. Em face do código da família (cinco avós, pelo menos estão me dizendo - ilustres sombras!) foi um crime gastar as vitaminas do tronco em serenatas e pagodes. Lá estava a fazenda, grande, poderosa, como um estabelecimento público, com sua lavoura à espera de cuidados moços. Sinto muito, avós. Eu não podia ouvir uma sanfona. ${ }^{18}$

Trechos como esse serviram para que algumas análises críticas, como a de John Gledson, estabelecessem uma interpretação sobre o romance mais voltada para o problema da passagem de uma organização social rural e tradicional para outra, urbana e moderna. Contudo, não se deve esquecer de pensar que essa decadência da aristocracia rural mineira passa por uma estilização no romance. Nesse exemplo, observa-se que a referência ao momento histórico e econômico é bastante forte, mas não é determinante, pois a construção do trecho assume a forma de uma confissão, quase um desabafo, instaurando assim uma perspectiva bastante íntima, na qual o personagemnarrador tenta resgatar de dentro de si o momento em que se iniciou o desvio do plano de futuro que honraria sua tradição familiar. O que se vê é que tudo só faz sentido na medida em que se liga à interioridade de Belmiro e às suas questões familiares: no fim da narração, o amanuense chega a pedir desculpas a seus ancestrais pelo seu lirismo excessivo e sua falta de praticidade na vida. Portanto, fica visível que as considerações de ordem prática, como o fracasso econômico e social do ex-morador da Vila Caraíbas, estão intimamente associadas ao seu sentimentalismo, que o fez incapaz de "ouvir uma sanfona” sem que a emoção tome conta de todo seu ser.

\footnotetext{
${ }^{18}$ ANJOS. O amanuense Belmiro, p. 27.
} 
Esse vaivém narrativo só se mostra possível devido ao caráter dramático do narrador, que explora as possibilidades inerentes ao texto narrativo: a partir de um processo poético, ele transfigura a si mesmo e torna-se outro, assumindo outro ponto de vista e dominando a cena, extrapolando a mera função de representação. ${ }^{19}$ Esse teor de dramaticidade fica explícito em alguns momentos do romance:

Afinal, são inúteis essas tentativas de análise e de interpretação de nós mesmos. Há, em nós, abismos insondáveis, que jamais exploraremos, onde se recolhem, pelo tempo que lhes apraz, as combinações múltiplas, várias, tantas vezes contraditórias, que compõem as formas sucessivas do nosso espírito. Explicar-me-ei, dizendo que hoje dormimos arlequim, amanhã acordaremos pierrô. As vestes ficaram guardadas em qualquer guarda-roupa de nossas profundezas onde se amontoam peças de indumentária que variam até ao infinito. ${ }^{20}$

O narrador do romance demonstra saber que a imobilidade proveniente da adoção de um ponto de vista que se pretende absoluto é algo extremamente limitador. Para o amanuense, é impossível fechar-se numa única identificação de si mesmo, pois a variabilidade de posições se mostra necessária para dar conta da multiplicidade do real, que solicita uma representação plural. Devido à dramatização dos caracteres que formam o mundo histórico-social, o narrador se reveste de variadas posturas e estratégias narrativas, para se haver com a diversidade qualitativa dos eventos narrados e expressar os valores da vida em sociedade. ${ }^{21}$

Valendo-se dessas reflexões formalmente irônicas, o narrador chega até a esboçar "teorizações" sobre essa constante interpenetração entre o indivíduo e a sociedade na criação e expressão artística, como quando fala de um sanfoneiro que tocava na rua:

Era precisamente por ali que estacionava outro sanfonista que não esmolava nem era cego, e tocava apenas por amor à arte, ou talvez para chorar mágoas. E chorava-as tão bem que cada um que o cercava sentia as suas mágoas igualmente choradas. $\mathrm{O}$ artista se revelava por esta forma perfeito, extraindo, dos seus motivos individuais, melodia ajustadas às necessidades da alma dos circunstantes, que ali iam buscar expressão para sentimentos indefiníveis que os povoavam e só se traduziam por frases musicais. ${ }^{22}$

\footnotetext{
${ }^{19}$ BRANDÃO. A invenção do romance, p. 126.

${ }^{20}$ ANJOS. O amanuense Belmiro, p. 101.

${ }^{21}$ SOUZA. O romance tragicômico de Machado de Assis, p. 7-11.

${ }^{22}$ ANJOS. O amanuense Belmiro, p. 33.
} 
Percebe-se assim que, para Belmiro, o artista perfeito é aquele que consegue estabelecer uma ponte entre os elementos fornecidos pela sua subjetividade e aqueles encontrados na realidade, ou seja, para ele, o bom criador é aquele que nem se fecha em si mesmo e nem se atém apenas à superfície das coisas. Nota-se que é justamente o modelo de configuração estética observável na estrutura de O amanuense Belmiro, o que nos permite dizer que tal passagem constitui-se como mais um exemplo no qual o narrador pensa a organização da narrativa. No romance, nos é apresentada uma concepção de composição estética que se afasta tanto da ânsia de totalidade descritiva do social quanto da mística subjetiva. Esse equilíbrio entre as duas formas de representação permite que o romance apresente uma noção de realidade nada simplificada, pois o mundo empírico não aparece no livro de maneira pictórica, ocupando o primeiro plano, e nem de modo que funcione apenas como um simples pano de fundo para as impressões e divagações de Belmiro, privilegiando-se apenas um tipo de construção de cunho psicológico.

\title{
CONCLUSÃO
}

Conforme foi possível observar, não parece ser plausível pensar $O$ amanuense Belmiro como um tipo de romance alheado da realidade e muito menos como mera tentativa de reprodução da realidade a partir do discurso literário. No livro atua uma configuração poética bastante ajustada, capaz de nos mostrar a obra literária como algo que vai além da sua redução ao plano real como algo imediato, uma vez que passou por um processo de mediação. Assim, vemos que as obras de arte "tornam-se aparições no sentido mais rico do termo, aparições de um outro, quando o acento incide sobre o caráter irreal da sua realidade”, 23

\begin{abstract}
Critics have usually defined Cyro dos Anjos’s $O$ amanuense Belmiro as an intimist novel, concerned with the recording of psychological experiences. However, as I intend to demonstrate, social reality is present in the narrative construction, by means of the mediation between its form and the social world.
\end{abstract}

\footnotetext{
${ }^{23}$ ADORNO. Teoria estética, p. 127.
} 
KEYWORDS

Form, intimism, reality, O amanuense Belmiro

\section{REFERÊNCIAS}

ADORNO, Theodor W. Palestra sobre lírica e sociedade. In: . Notas de Literatura I. Trad. Jorge de Almeida. São Paulo: Duas Cidades/Ed. 34, 2003. p. 65-90.

ADORNO, Theodor W. Teoria estética. Trad. Artur Morão. Lisboa: Edições 70, 2011.

ANJOS, Cyro dos. O amanuense Belmiro. Belo Horizonte: Livraria Garnier, 2001.

AUERBACH, Erich. Mimesis: a representação da realidade na literatura ocidental. Trad. J. Guinsburg. São Paulo: Perspectiva, 2009.

BRANDÃO, Jacyntho Lins. A invenção do romance. Brasília: Ed. UnB, 2005.

CANDIDO, Antonio. Estratégia. In: . Brigada ligeira. Rio de Janeiro: Ouro sobre Azul, 2004. p. 73-80.

LUKÁCS, Georg. A característica mais geral do reflexo lírico. In: Arte $e$ sociedade: escritos estéticos 1932-1967. Trad. Carlos Nelson Coutinho e José Paulo Netto. Rio de Janeiro: Ed. UFRJ, 2009. p. 245-248.

MERQUIOR, José Guilherme. A astúcia da mimese: (ensaios sobre lírica). Rio de Janeiro: Topbooks, 1997.

NOBILE, Ana Paula Franco. A recepção crítica de O amanuense Belmiro, de Cyro dos Anjos (1937). São Paulo: Annablume, 2005.

SOUZA, Ronaldes de Melo e. O romance tragicômico de Machado de Assis. Rio de Janeiro: EdUERJ, 2006. 